Ege Tıp Dergisi / Ege Journal of Medicine 2021; 60 (4): 407-411

\title{
Oosit toplama sırasındaki folikül yıkamanın fertilite prezervasyonu siklusları sonuçlarına etkisi, retrospektif çalışma
}

\author{
The effect of follicle flushing during oocyte retrieval on fertility preservation cycle \\ outcomes, retrospective study \\ \begin{tabular}{l} 
Volkan Emirdar ${ }^{1}$ Ferruh Acet ${ }^{2} \oplus$ \\
${ }^{1}$ İmir Ekonomi Üniversitesi, Medical Park Hastanesi Kadın Hastalıkları ve Doğum Bölümü, İzmir, Türkiye \\
${ }^{2}$ Ege Üniversitesi Tıp Fakültesi Kadın Hastalıkları ve Doğum Anabilim Dalı, İzmir, Türkiye \\
\hline \hline
\end{tabular}
}

\section{ÖZ}

Amaç: Kanser hastalarının kemoterapi sonrası yumurtalık rezervlerini kaybetme riski altında olduğu göz önüne alındığında, fertilite prezervasyonu (FP) döngülerinde oosit kalitesini en üst düzeye çıkarmak çok önemlidir. Amacımız, FP için letrozol ve gonadotropinler ile oositleri veya embriyoları korumak için kontrollü yumurtalık stimülasyonu uygulanan kadınlarda elde edilen oosit ve embriyo sayısını maksimize etmede foliküler yıkamanın yararlılığını belirlemekti.

Gereç ve Yöntem: Fertilite prezervasonu planlanan meme kanserli olgular retrospektif olarak tarandı. Çift lümenli yıkama yaklaşımı (ÇLY) kullanılarak oositlerin aspire edildiği 11 döngü, oositlerin tek lümenli aspirasyon (TLA) yoluyla alındığı yaş uyumlu 31 döngü ile karşılaştırıldı. $10 \mathrm{~mm}$ ve üzerinde ölçüm yapılan tüm foliküller aspire edildi. ÇLY grubunda, foliküller 6 defaya veya oosit elde edilene kadar yıkandı.

Bulgular: Ortalama yaş ve anti-müllerian hormon (AMH) değerleri ÇLY ve TLA grupları arasında benzerdi (sırasıyla, yaş:39,8 $\pm 0,48 / 37,9 \pm 0,74 ; p=0,162 ; A M H: 1,69 \pm 0,37 / 1,47 \pm 0,25 \mathrm{ng} / \mathrm{mL}$ $\mathrm{p}=0,635)$. Pik estradiol seviyeleri ÇLY grubunda anlamlı olarak daha yüksekti (ÇLY / TLA: 1022,66 \pm $205,45 / 715,5 \pm 33,69 \mathrm{pg} / \mathrm{mL}, \mathrm{p}=0,026$ ). Toplam gonadotropin dozu ( ÇLY / TLA: $5345 \pm 344 / 5017 \pm$ $108 \mathrm{IU}, p=0,236$ ) ve toplam letrozol dozu (CLLY / TLA: 59,0 $\pm 2,84$ / 57,9 $\pm 1,08 \mathrm{mg}, \mathrm{p}=0,633$ ) her iki grupta benzerdi. Tetikleme öncesi ultrasonografide $10 \mathrm{~mm}$ üzerindeki folikül sayısı temel alındığında benzer sayıda folikül saptandı $(16,2 \pm 1,2 / 12,5 \pm 1,3 ; p=0,16)$. Çift lümenli yıkama yaklaşımı ile daha yüksek toplam oosit sayısı $(17,4 \pm 2,3 / 10,9 \pm 1,2 ; p=0,015)$ ve daha yüksek sayıda olgunlaşmamış oosit elde edildi $(8,36 \pm 1,12 / 3,53 \pm 0,45 ; p<0,001)$. Ancak dondurularak saklanan embriyoların sayısındaki fark istatistiksel anlamlılığa ulaşmadı $(7,2 \pm 1,94 / 5,2 \pm 0,79 ; p=0,279)$.

Sonuçlar: Fertilite prezervasyonu döngülerinde ÇLY kullanımı, küçük foliküllerden elde edilen immatür oosit sayısını arttırabilir. Çift lümenli yıkama yaklaşımının nihai embriyo verimini artırmadaki değeri, FP uygulanan kadınlar arasında daha geniş prospektif çalışmalarda araştırılmalıdır.

Anahtar Sözcükler: Oosit, meme kanseri, in vitro fertilizasyon.

* Bu çalışma, 17-21 Ekim 2015 tarihlerinde Baltimore, ABD' de düzenlenen Amerikan Üreme Tıbbı Cemiyeti Kongresi'nde sözlü bildiri olarak sunulmuştur.

\section{ABSTRACT}

Aim: In oncology cases, chemo-radiotherapy treatments affect the ovarian reserve negatively, and fertility-preserving (FP) approaches are recommended in this patient group. Our purpose was to evaluate the efficacy of follicular flushing to increase oocyte and embryo retrieval in women undergoing controlled ovarian stimulation to preserve oocytes or embryos using gonadotropin in combination with aromatase inhibitors for FP.

\footnotetext{
Sorumlu yazar: Volkan Emirdar

İzmir Ekonomi Üniversitesi, Medical Park Hastanesi Kadın

Hastalıkları ve Doğum Bölümü, İzmir, Türkiye

E-posta: volkanemirdar@yahoo.com

Başvuru tarihi: 16.10.2021 Kabul tarihi: 14.11.2021
} 
Materials and Methods: In our study, breast cancer cases were screened retrospectively. Eleven cycles in which oocytes were retrieved using the Double-lumen washing technique (DLF) in the same age group were compared with the cycle in which the oocytes were aspirated by single-lumen aspiration (SLA). All follicles displayed above $10 \mathrm{~mm}$ were aspirated. In the DLF group, oocyte was washed up to retrieval or up to 6 times.

Results: Mean age and anti-mullerian hormone (AMH) levels were not significantly different in both groups (age: $39.8 \pm 0.48$ vs. $37.9 \pm 0.74$ years; $p=0.162$; $A M H: 1.69 \pm 0.37$ vs. $1.47 \pm 0.25 \mathrm{ng} / \mathrm{mL}$; $p=0.635$, respectively), maximum estradiol levels were significantly higher in the flushing group. (DLF vs SLA: $1022.66 \pm 205.45$ vs $715.5 \pm 33.69 \mathrm{pg} / \mathrm{mL} ; p=0.026$ ). Total dose of gonadotropins (DLF vs. SLA: $5345 \pm 344$ vs. $5017 \pm 108 \mathrm{IU} ; p=0.236$ ) and total dose of aromatase inhibitors (DLF vs. SLA: $59.0 \pm 2.84$ vs. $57.9 \pm 1.08 \mathrm{mg} ; p=0.633$ ) were not different. According to the number of follicles $>10$ $\mathrm{mm}$ on the trigger day, a similar number of follicles was stated (DLF vs. SLA: $16.2 \pm 1.2$ vs. $12.5 \pm 1.3$; $p=0.16)$. The total number of oocytes retrieved in the DLF group (17.4 \pm 2.3 vs $10.9 \pm 1.2 ; p=0.015$; respectively) and metaphase 1 oocytes $(8.36 \pm 1.12$ vs $3.53 \pm 0.45 ; p<0.001)$ were statistically significantly higher. However, the number of cryopreserved embryos was statistically similar in both groups. (DLF vs. SLA: $7.2 \pm 1.94$ vs. $5.2 \pm 0.79 ; p=0.279$ ).

Conclusions: Administration of DLF in ovarian stimulation cycles in oncology patients may increase the number of immature oocytes retrieved from non-dominant follicles. The value of DLF in increasing the total number of embryos should be investigated in randomized controlled trials in patients undergoing fertility preservation.

Keywords: Oocyte, breast cancer, in vitro fertilization.

* This research was presented as an oral presentation at American Society for Reproductive Medicine Annual Congress, held on Oct $17^{\text {th }}-121^{\text {st }}, 2015$ in Baltimore, USA.

\section{GiRiş}

Meme kanseri kadınlarda en sık görülen malignitedir (1). ABD'den alınan en son istatistiklere göre, en son beş yıllık dönemde (2012-2016) ölüm oranlarında düşüş olmakla birlikte insidansta, özellikle genç yaş grubunda, $\% 0,3$ oranında bir artış bildirilmiştir (2).

Meme kanserli genç kadınların çoğu, gonadotoksik ajanlar içeren adjuvan kemoterapiye intiyaç duyar (3). Bu tür tedavilere bağlı olarak yumurtalık rezervinin azaldığı literatürde tanımlanmıştır. Yumurtalık rezervinin azalması hastanın yaşı, kemoterapötik ilaçların tipi ve kümülatif dozu gibi birçok faktöre bağlıdır. Alkilleyici ajanlar en gonadotoksik ilaçlardır ve primordial foliküllere zarar verebilir (4). Yaş en önemli risk faktörü olmakla birlikte daha genç kadınlar da gonadotoksik tedavilere bağlı olarak yumurtalık rezervlerinin azalması nedeniyle infertilite karşımıza çıkabilir. Kanser tedavilerinden sonra doğurganlığın devam etmesi genç kadınlar için en büyük sorunlardan biridir. Infertilite ve prematür ovaryan yetmezlik riski nedeniyle, birçok kılavuz, gonadotoksik tedavilere başlamadan önce fertilite prezervasyonu seçeneklerini tartışmaya teşvik etmektedir (5).

Çift lümenli iğne ile foliküler yıkama, bir in vitro fertilizasyon (IVF) programında folikül ponksiyonu sırasında, foliküler sıvının ilk aspirasyonundan sonra delinme iğnesini değiştirmeden içine salin enjekte ederek folikülün yıkanmasını içeren bir tekniktir. Doğrudan foliküler ponksiyon, her bir folikülde bulunan oositlerin sadece \%60-80'ini toplayabilir (6). Teoride, foliküler yıkama, kalan içeriğin aspire edilmesini sağlayarak bu oranı arttırabilir (7). Ek bir oosit meme kanseri hastalarında başarı şansını önemli ölçüde artırabilir.

Bu çalışmanın amacı; meme kanseri nedeniyle fertilite prezervasyonu yapılan hastalarda doğrudan aspirasyon ile çift lümenli iğne ile foliküler yıkamadan sonra oosit toplama oranını retrospektif olarak karşılaştırmaktır.

\section{GEREÇ ve YÖNTEM}

Bu retrospektif kohort çalışmaya, İzmir Ekonomi Üniversitesi Medicalpark Hastanesi Tüp Bebek Merkezi'ne fertilite prezervasyonu için sevk edilen ve 2012-2020 yılları arasında embriyo ve/veya oosit kriyoprezervasyonu uygulanan 42 meme hastası dahil edildi. Dahil edilme kriterleri; 18 45 yaş arası, onkolojik tedavilerden önce oosit/embriyo kriyoprezervasyonu yapılmış, yeni tanı almış Evre 0 - 3 meme kanseri hastaları idi. Illeri evre ve/veya metastatik hastalık dişlama kriterleriydi. Ovaryan stimülasyon öncesi tüm hastalardan onkoloji konsültasyonu istendi. Fertilite prezervasyonu (FP) için ilk konsültasyondan sonra, ilgilenen hastalara oosit veya embriyo kriyoprezervasyonu için kontrollü ovaryan 
hiperstimulasyon uygulandı. Tüm hastalar onkolojik tedavilerinden önce FP prosedürleri için ve ayrıca bu retrospektif çalışma için bilgilendirilmiş onam verdi. Bu çalışma Ege Üniversitesi Etik Kurulu tarafından onaylanmıştır(E.360950-15.10.2021).

Kontrollü ovaryan stimulasyon, yumurtalık rezervine göre 150 - 375 IU dozlarında rekombinant folikül stimülan hormon (recFSH) ile yapıldı. Letrozol, meme kanseri östrojen reseptör durumundan bağımsız olarak stimülasyon boyunca kullanıldı. Siklus boyunca serum estradiol seviyeleri ve foliküler boyut ölçüldü. Gonadotropin salgılatıcı hormon (GnRH) antagonisti, folikül çapı 12 mm'ye ulaşır ulaşmaz başlandı ve ovulasyon tetiklenene kadar devam edildi. İki folikülün çapı >18 mm'ye ulaştığında rekombinant insan koryonik gonadotropin (hCG) enjeksiyonu ile ovulasyon tetiklendi.

Basit aspirasyon grubu: $35 \mathrm{~cm}$ tek lümenli 17 gauge iğne ile kliniğin standart protokolü izlenerek ponksiyon yapıldı.

Çift lümen yıkama (ÇLY) grubu: İlk folikül 35 cm'lik çift lümenli 17 gauge iğne kullanılarak aspire edildi ve sıvı, folikül numarası ile etiketlenmiş bir tüpte toplandı, ardından tüp, bir yıkama sıvısı kullanılarak aynı folikülden çıkan sıvıyı toplamak için değiştirildi. Diğer foliküller için işlem tekrarlandı.

Tek lümen aspirasyon (TLA) grubu: Bu gruptaki hastalarda sadece folikül $35 \mathrm{~cm}$ 'lik tek lümenli 17 gauge iğne kullanılarak aspire edildi ve sıvı, değerlendirme için direkt laboratuvara gönderildi.

Tüm hastalarda $-150 \mathrm{~mm}$ Hg'ye ayarlanmış bir vakum pompası (Cook@ K-MAR-5200) kullanılarak foliküler sıvının aspirasyonu yapıldı. Biyolog, yıkama ortamında toplanan oositleri tespit ederek tüm tüplerde bulunan oosit sayısını saydı, ayrıca toplanan oositlerin her birinin maturasyon derecesi de kaydedildi. Tüm hastalara intrasitoplazmik sperm enjeksiyonu yapılarak elde edilen embriyolar donduruldu.
Birincil değerlendirme kriteri, elde edilen oosit sayısıydı. İkincil değerlendirme kriterleri, fertilizasyon oranı ve dondurulabilir embriyo sayısıydı.

Tüm istatistiksel analizler Statistical Package for the Social Sciences (SPSS) v.22.0 for Windows (SPSS, Inc., Chicago, IL, ABD) kullanılarak yapıldı. Hasta gruplarının temel özelliklerini tanımlamak ve karşılaştırmak için tanımlayıcı istatistikler kullanıldı. Sürekli değişkenlerin normallik varsayımını kontrol etmek için ShapiroWilk Normallik testi kullanıldı. Foliküler yıkama ve kontrol gruplarının sonuçları, veri dağılımının normalliğine göre bağımsız örnek $t$ testi veya Wilcoxon runk-sum (Mann-Whitney $U$ ) testi ile karşılaştırıldı. .05'ten küçük bir $\mathrm{p}$ değeri istatistiksel olarak anlamlı kabul edildi.

\section{BULGULAR}

Tablo-1'de hastaların siklus karakteristikleri ve fertilite sonuçları görülmektedir. Ortalama yaş ve anti-müllerian hormon (AMH) değerleri ÇLY ve TLA grupları arasında benzerdi. (sırasıyla, yaş:39,8 $\pm 0,48$ vs $37,9 \pm 0,74 ; p=0,162 ; A M H$ : $1,69 \pm 0,37$ vs $1,47 \pm 0,25 \mathrm{ng} / \mathrm{mL}, p=0,635)$, pik estradiol seviyeleri ÇLY grubunda anlamlı olarak daha yüksekti. (ÇLY vs TLA: $1022,66 \pm 205,45$ vs $715,5 \pm 33,69 \mathrm{pg} / \mathrm{mL}, \quad \mathrm{p}=0,026)$. Toplam gonadotropin dozu (ÇLY / TLA: $5345 \pm 344$ / $5017 \pm 108 \mathrm{IU} ; p=0,236$ ) ve toplam letrozol dozu (ÇLY / TLA: 59,0 $\pm 2,84$ / 57,9 $\pm 1,08$ mg; $\mathrm{p}=0,633$ ) her iki grupta benzerdi. Tetikleme öncesi ultrasonografide $10 \mathrm{~mm}$ üzerindeki folikül sayısı temel alındığında benzer sayıda folikül saptandı $(16,2 \pm 1,2 / 12,5 \pm 1,3 ; p=0,16)$. ÇLY ile daha yüksek toplam oosit sayısı (17,4 $\pm 2,3$ / $10,9 \pm 1,2 ; p=0,015)$ ve daha yüksek sayıda olgunlaşmamış oosit elde edildi $(8,36 \pm 1,12$ / $3,53 \pm 0,45 ; p<0,001)$. Ancak dondurularak saklanan embriyoların sayısındaki fark istatistiksel anlamlılığa ulaşmadı $(7,2 \pm 1,94$ / 5,2 $\pm 0,79 ; p=0,279$ ).

Tablo-1. Siklus karakteristikleri ve fertilite prezervasyon sonuçları.

\begin{tabular}{|c|c|c|c|}
\hline & $\begin{array}{l}\text { ÇLY* (n=11) } \\
\text { (Ort } \pm s d)\end{array}$ & $\begin{array}{l}\operatorname{TLA}^{\star *}(n=31) \\
(\text { Ort } \pm s d)\end{array}$ & P değeri \\
\hline Yaş (yıl) & $39,8 \pm 0,48$ & $37,9 \pm 0,74$ & 0,163 \\
\hline $\mathrm{AM}^{3} \mathrm{H}^{\star \star *}(\mathrm{ng} / \mathrm{mL})$ & $1,6 \pm 0,37$ & $1,4 \pm 0,25$ & 0,635 \\
\hline Toplam FSH ${ }^{\pi \times x}$ dozu (IU) & $5345 \pm 344$ & $5017 \pm 108$ & 0,236 \\
\hline Toplam Letrozol dozu (mg) & $59,09 \pm 2,84$ & $57,90 \pm 1,08$ & 0,633 \\
\hline Pik E2 $^{\star \star \star \star x \star}$ seviyesi $(\mathrm{pg} / \mathrm{mL})$ & $1022,46 \pm 205,45$ & $715,51 \pm 33,69$ & 0,026 \\
\hline Tetikleme günü folikül sayısı & $16,2 \pm 1,2$ & $12,5 \pm 1,4$ & 0,166 \\
\hline Toplanan oosit sayısı & $17,4 \pm 2,34$ & $10,9 \pm 1,26$ & 0,015 \\
\hline Toplanan immatür oosit sayısı & $8,36 \pm 1,12$ & $3,53 \pm 0,45$ & $\mathrm{p}<0,001$ \\
\hline Dondurulan embriyo sayısı & $7,2 \pm 1,94$ & $5,2 \pm 0,79$ & 0,279 \\
\hline
\end{tabular}

${ }^{*}$ ÇLY: Çift lümenli yıkama grubu, ${ }^{* *}$ TLA: Tek lümenli aspirasyon kontrol grubu, ${ }^{* * *}$ FSH: Folikül stimülan hormon, ${ }^{* * * *}$ AMH: Antimüllerian hormon, ${ }^{x+* *}$ Estradiol 


\section{TARTIŞMA}

Yapmış olduğumuz bu tek merkezli çalışmada amaç, meme kanserli olgularda FP için yapılan oosit veya embriyo dondurma işlemi sırasında foliküler yıkamanın elde edilen oosit ve embriyo sayısı üzerindeki etkinliğini değerlendirmekti. Bu amaçla, FP yapılan 42 in vitro fertilizasyon siklusunu geriye dönük olarak analiz ettik. Taranan hastalarda, foliküler yıkamanın total oosit sayısı üzerinde istatistiksel olarak anlamlı bir pozitif etkisi olduğunu gösterdik ancak elde edilen metafaz 2 oosit sayısı ve embriyo sayısında herhangi bir farklılık saptamadık.

Şu anki bilgilerimize göre yapmış olduğumuz bu çalışma meme kanserli olgularda foliküler yıkamanın siklus sonuçları üzerine etkisini gösteren ilk çalışma idi.

Daha önce yapılan randomize kontrollü bir çalışmada Haydardedeoğlu ve arkadaşları foliküler yıkamanın siklus sonuçları üzerinde anlamlı bir etkisi olmadığını belirtti. Bununla birlikte, bu çalışmada yalnızca normal yanıt veren hastaları incelemişlerdi (8). Çalışmamızda, basit aspirasyon grubunda foliküler yıkama grubuna göre anlamlı olarak daha düşük olan tetikleme gününde serum estradiol seviyeleri dışında her iki grup da tüm temel kriterler açısından benzer saptandı. Bu hasta grubunda, yıkamanın potansiyel olarak toplanan oosit sayısını maksimuma çıkarabileceğine yaygın olarak inanılsa da, doğrudan aspirasyon ile karşılaştırıldığında, yıkama yapılanlar arasında matür oosit sayısında ve dondurulan embriyo sayısında hiçbir fark saptamadık.

Önceki randomize kontrollü çalışmalar ve metaanalizler, elde edilen oosit sayısı üzerinde yıkamanın faydası olmadığını ifade ederken, uzun işlem süresi dışında herhangi bir olumsuz etki de göstermediler (9). Mok-Lin ve arkadaşları ise yapmış oldukları çalışmada daha az embriyo eldesi ve daha düşük gebelik sonuçları bildirdiler (10). Bizim yapmış olduğumuz çalışmada ise elde edilen embriyo sayısında herhangi bir farklılık saptanmadı.

Çalışmalar, tek başına foliküler sıvı aspirasyonu ile foliküler yıkamanın birbirine üstünlüklerinin olmadığını göstermiştir. Teknik, cerrahların tercihlerine bağlı olabilir. Yapılan bir çalışmada tek başına aspirasyon ile foliküler yıkama arasında gebelik oranlarında fark bulunmamıştır (11).
Ameliyat süresi, anestezik ajan kullanımı ve ayrıca ameliyat maliyetinde azalma gibi aspirasyonun yıkamaya göre bir dizi teorik avantajı vardır. Buna ek olarak, oosit hasarı ile birlikte potansiyel bir pelvik enfeksiyon riski vardır. Ancak bu teorik risklere, ameliyat süresinde hafif artış dışında karşılaşılmadı, anestezi kullanım protokolümüzde herhangi bir değişiklik olmadı.

In vitro fertilizasyon veya intrasitoplazmik sperm enjeksiyonu uygulanan kadınlarda tek başına aspirasyon ile foliküler yıkamanın etkinliğini değerlendiren bir Cochrane derlemesinde orta kalitede kanıtlar, foliküler yıkama ile canlı doğumun sonuçlarında çok az fark olduğunu veya hiç fark olmadığını gösterdi. Yine aynı derlemede orta kalitede kanıtlar, tek başına aspirasyona kıyasla foliküler yıkama ile elde edilen oosit sayısında çok az fark olduğunu veya hiç fark olmadığını gösterdi. Oosit toplama sürecinin, bu kanıtın çok düşük kalitede olmasına rağmen, tek başına aspirasyona göre foliküler yıkama ile önemli ölçüde daha uzun sürdüğü kaydedildi. Toplam embriyo sayısı, dondurularak saklanan embriyo sayısı veya klinik veya devam eden gebelik oranlarında hiçbir farklılık saptanmadı (12). Bizim yapmış olduğumuz bu çalışmada da elde edilen total oosit sayısı anlamlı oranda yüksek iken matür oosit ve embriyo sayısında farklılık saptanmadı.

$\mathrm{Bu}$ çalışmanın sınırlayıcı yanı geriye dönük dosya taraması ve sınırlı hasta sayısı idi. Çalışmanın güçlü yanı ise tek merkezli bir çalışma olması, FP yapılan özellikli bir hasta grubunu değerlendirmesi ve hasta gruplarının homojenliği idi.

\section{SONUÇ}

Foliküler yıkama yapılmazsa, oosit alımı için gereken süre daha kısa olacaktır. Çok sayıda folikülü olan hastalar için, gebelik şansı yıkama olmadan değişmeyebilir, ancak folikülü az olan hastalarda, sadece bir ekstra oosit sonucu etkileyebileceğinden, her oositin alınması arzu edilir. Gonadotoksik tedavi planlanan bu hasta grubunda elde edilen her bir oosit FP için hastaya bir şans sunacaktır.

Çıkar çatışması: Çalışmada herhangi bir kurum ve kişi ile çıkar çatışması bulunmamaktadır. 


\section{Kaynaklar}

1. Bray F, Ferlay J, Soerjomataram I, Siegel RL, Torre LA, Jemal A. 2018. Global cancer statistics 2018: GLOBOCAN estimates of incidence and mortality worldwide for 36 cancers in 185 countries. CA: A Cancer Journal for Clinicians, 68: 394-424.

2. Kudela E, Samec M, Kubatka P, Nachajova M, Laucekova Z, Liskova A, et al. 2019. Breast Cancer in Young Women: Status Quo and Advanced Disease Management by a Predictive, Preventive, and Personalized Approach. Cancers (Basel), 11: 1791.

3. Kasum M, Beketić-Orešković L, Peddi PF, Orešković S, Johnson RH. 2014. Fertility after breast cancer treatment. European Journal of Obstetrics Gynecology and Reproductive Biology, 173: 13-8

4. Rodriguez-Wallberg KA and Oktay K. 2010. Fertility preservation in women with breast cancer. Clinical Obstetrics and Gynecology, 53: 753-762.

5. Dolmans MM, Lambertini M, Macklon KT, Almeida Santos T, Ruiz-Casado A, Borini A, et al. 2019. EUropean REcommendations for female FERtility preservation (EU-REFER): A joint collaboration between oncologists and fertility specialists. Critical Reviews in Oncology/Hematology, 138: 233-240.

6. Baber R, Porter R, Picker R, Robertson R, Dawson E, Saunders D. Transvaginal ultrasound directed oocyte collection for in vitro fertilization: successes and complications. J Ultrasound Med 1988; 7 (7): 377-9.

7. Waterstone $\mathrm{JJ}$, Parsons $\mathrm{JH}$. A prospective study to investigate the value of flushing follicles during transvaginal ultrasound-directed follicle aspiration. Fertil Steril 1992; 57 (1): 221-3.

8. Haydardedeoglu B, Cok T, Kilicdag EB, Parlakgumus AH, Simsek E, Bagis T. In vitro fertilizationintracytoplasmic sperm injection outcomes in single versus double-lumen oocyte retrieval needles in normally responding patients: a randomized trial. Fertil Steril 2011; 95 (2): 812-4.

9. Wongtra-Ngan S, Vutyavanich T, Brown J. Follicular flushing during oocyte retrieval in assisted reproductive techniques. Cochrane Database Syst Rev 2010:CD004634.

10. Evelyn Mok-Lin, Anate Aelion Brauer, Glenn Schattman, Nikica Zaninovic, Zev Rosenwaks, and Steven Spandorfer Follicular flushing and in vitro fertilization outcomes in the poorest responders: a randomized controlled trial Human Reproduction, Vol.28, No.11 pp. 2990-2995, 2013

11. Scott RT, Hofmann GE, Muasher SJ, Ascota AA, Kreiner DK, Rosenwaks Z. 1989. A prospective randomized comparison of single and double - lumen needles for transvaginal follicular aspiration. Journal of In Vitro Fertilisation and Embryo Transfer 6: 98 - 100.

12. Ektoras Georgiou, Pedro Melo, Julie Brown, Ingrid E Granne 2018. Follicular flushing during oocyte retrieval in assisted reproductive techniques Cochrane Database Syst Rev 2018 Apr 26; 4 (4): CD004634. 